\title{
Close and regular surveillance is key to prevent severe complications for Peutz- Jeghers syndrome patients without gastrointestinal polyps: case report of a novel STK11 mutation (c.471_472delCT) in a Chinese girl
}

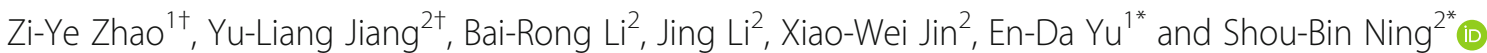

\begin{abstract}
Background: Peutz-Jeghers syndrome (PJS) is a Mendelian disease characterized by gastrointestinal hamartomas, mucocutaneous pigmentation (MP), and increased cancer risk. Serine/threonine kinase 11 (STK11) is the only validated causative gene in PJS. Clinical observation reveals MP and intussusception in childhood are more frequent and severe than in adults.

Case presentation: We report here a girl without a positive family history, who grew oral and fingertip MP at her age of 2 and got abdomen dull pain from 7 years old. Endoscopy revealed no obvious polyps in the stomach or the colon until 10 years old, when she received enteroscopy. Tens of polyps were resected during enteroscopy, and pathological examination confirmed them hamartomas. A heterozygous deletion in STK11, c.471_472delCT, was detected in the proband but not in her parents, which is not recorded in databases.

Conclusion: The mutation we reported here is a novel one and a de-novo one, so our results enlarge the spectrum of STK11. We speculate close and regular endoscopy especially enteroscopy is necessary for complication prevention when the former endoscopy discovers no polyps temporarily in a child of suspect PJS.
\end{abstract}

Keywords: Peutz-Jeghers syndrome, STK11 gene, Hamartoma, Polyposis, Enteroscopy

\section{Background}

Peutz-Jeghers Syndrome (PJS, OMIM 175200) is an autosomal dominant disorder characterized by gastrointestinal (GI) hamartomatous polyps, mucocutaneous pigmentation (MP) and an increased risk for the development of GI and various extra-GI malignancies [1]. Germline mutations in serine/threonine kinase 11 (STK11, OMIM 602216) gene which impairs its kinase activity are considered to cause PJS, and more than 400

\footnotetext{
* Correspondence: endayu@yeah.net; ningshoubin@126.com

${ }^{\dagger}$ Equal contributors

'Department of Colorectal Surgery, Changhai Hospital, 168 Changhai Rd, Shanghai 200433, China

${ }^{2}$ Department of Gastroenterology, Airforce General Hospital of PLA, 30 Fucheng Rd, Beijing 100142, China
}

of them identified in patients with PJS have been recorded in Human Gene Mutation Database (HGMD, http://www.hgmd.cf.ac.uk).

Among reported cases of PJS, more than $30 \%$ of them develop polyp-related symptoms by age 10 years and $50 \%$ by 20 years [2]. In children with PJS, intussusception due to GI polyps is the most important symptom, while PJS-associated tumors are primary in adults [3]. van Lier et al.[4] reported cumulative intussusception risk in PJS of $15 \%$ by age 10 years and $50 \%$ by age 20 . Because of this background, it is important to make a set of strategies for screening and surveillance in young PJS patients, especially when family history is absent. 
Here, we report a 11 year-old PJS girl without a positive family history characterized by MP and GI polyps, and Sanger sequencing confirmed a novel mutation in STK11 (c.471_472delCT) as the causative one.

\section{Case presentation}

\section{Clinical information}

The 11 year-old girl of Hui nationality (a race of Muslim in China) from East China came to Airforce General Hospital at her age of 10, who was diagnosed of suspect PJS in other hospital. Multiple MP in lips, cheeks and fingertips were observed by her families when she was 2 years old, and the occasional seizure of abdominal dull pain did not draw their attention since this family had no history of PJS. At the age of 7, the girl was brought to a major pediatric hospital, but gastroscopy and colonoscopy revealed no obvious polyps, after which the diagnosis of PJS was only suspected but not confirmed. At her age of 10, paroxysmal periumbilical cramps lasted for 2 days, which convinced the parents arranged their daughter a thorough examination. After being referred to our department, we arranged her for double-balloon enteroscopy (DBE). DBE both anterograde and retrograde revealed tens of polyps in the gastric fundus and 4 polyps in the colon, within which the biggest one was as large as $3 \mathrm{~cm}$ in diameter, and at the same time endoscopic polypectomy was performed (Fig. 1a). Postprocedural pathological examination confirmed them hamartomas, and the diagnosis of PJS was affirmed (Fig. 1d). The symptoms relieved largely after enteroscopy, and she lives a life uneventfully after that.

\section{Mutation analysis}

During her hospitalization, we recruited her in our PJS surveillance and research cohort and collected the blood samples of herself and her parents. Written informed

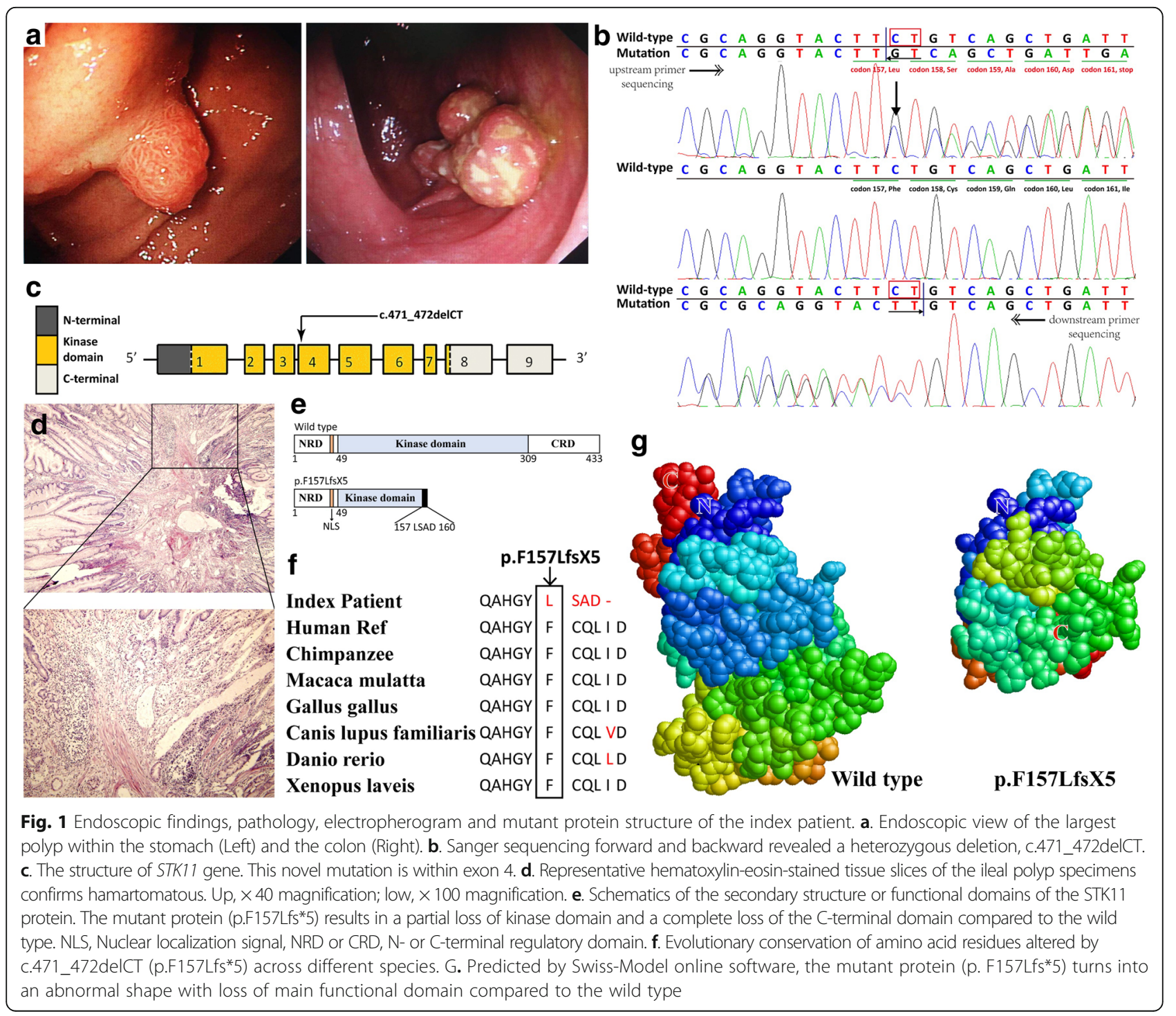


consents were obtained from her parents as the girl's guardians. Genomic DNA extraction, polymerase chain reaction (PCR), purification and sequencing were performed essentially as previously described, mainly using animal genomic DNA kit (TSP201), gel extraction kit (GE0101), and $2 \times$ modified DNA polymerase mix (TSE004, TsingKe Biotech, Beijing, China) [5]. The results were used to performance sequence alignment according to STK11 gene sequence (NP_000446.1 and NM_000455.4 in GRCh38.p7).

In order to rule out polymorphisms, 100 chromosomes from 50 unrelated control individuals who came to our department for gastric polyps treatment in September, 2016 were also screened for the presence of the mutation. All biological samples were collected after written consent being acquired. This study was approved by the Medical Ethics Committee, Airforce General Hospital of PLA.

A survey of STK11 gene revealed a heterozygous germline deletion c.471_472delCT in exon 4 in the patient's genomic DNA (Fig. 1b and c), while it was not detected in the parents' or the 50 unrelated control individuals'. This mutation has not been reported in literatures or recorded in mutation databases such as dbSNP, ClinVar and HGMD. It causes a translational frameshift, and a premature stop codon appears in codon 161 (p. F157Lfs*5), which results in a partial loss of kinase domain and a complete loss of the C-terminal domain compared to the wild type (Fig. 1e).

\section{Structure prediction of the mutant protein and analysis of evolutionary conservation of amino acid residues}

The homology modeling programs, Swiss-Model online software (http://swissmodel.expasy.org), was used to develop an appropriate model to mimic the effects of the mutated region [6]. Evolutionary conservation of amino acid residues altered was analyzed by comparing across different species (https://www.ncbi.nlm.nih.gov/protein/STK11).

Predicted by Swiss-Model online software, the mutant protein turns into an abnormal shape and loses main functional domains compared to the wild type (Fig. 1g). Evolutionary conservation analysis of amino acid residues showed these impaired amino acid residues were most evolutionary conserved (Fig. 1f). Taken together, this mutation is considered as a novel "pathogenic" one in STK11 causing PJS according to American College of Medical Genetics and Genomics (ACMG) classification system (Table 1).

\section{Discussion and conclusions}

In this report, we revealed a novel mutation in STK11 causing PJS in an 11 year-old girl without a positive family history. The mutation was not recorded in databases, and it was not detected in her patients or 50 unrelated control individuals. Furthermore, structure prediction
Table 1 Classification of multiple evidences about the novel mutation

\begin{tabular}{ll}
\hline Evidences & C.471_472delCT \\
\hline Population data & Absent in 50 controls and population databases (PM2) \\
Computational & Predicted null variant (frameshift mutation included) \\
and predictive data & in STK11 where LOF is a mechanism of PJS (PVS1) \\
Functional data & Not applicable \\
Segregation data & Cosegregation with PJS (PP1) \\
De novo data & $\begin{array}{l}\text { De novo (without paternity \& maternity confirmed) } \\
\text { (PM6) }\end{array}$ \\
Conclusion & Pathogenic (1 PVS1 and 2 PM and 1 PP) \\
\hline
\end{tabular}

and evolutionary conservation analysis present the pathological effect of it, we conclude that this mutation is disease-specific and not a polymorphic variant of the STK11 gene.

PJS is named after two physicians who made great contributions to this disorder. Peutz described a family with autosomal dominant inheritance of GI polyposis and pigmented mucous membranes, and Jeghers defined the coexistence of MP and GI polyposis as a distinct clinical entity [7]. The pathogenic gene, STK11, was first cloned in 1997 [8], which encodes a 433-amino-acidresidue protein acting as a tumor suppressor. With the help of direct sequencing and multiplex ligationdependent probe amplification (MLPA), the mutation detection rate of STK11 in PJS is raised to over 60\% [9]. Among reported mutations, frameshift or nonsense ones are most common types. The STK11 protein is mainly comprised of an N-terminal non-catalytic domain, a catalytic kinase domain, and a C-terminal non-catalytic regulatory domain [10]. Among reported STK11 mutations (HGMD), most variants are located in the region of catalytic kinase domain (amino acids 49-309) which leads to the loss of kinase activity [11]. In this case, the mutant protein lacks main functional domains compared to the wild type, so the novel mutation probably a pathogenic one. This mutation broadens the pathological mutation spectrum of STK11 gene. Till now, no certain relationship between genotype and phenotype has been determined (Table 2), which should be further explored through continuous work.

For children without a family history, PJS is hard to diagnose until they suffer from severe GI complications [12]. On this condition, an open surgery is often unpreventable. When the diagnosis of PJS is suspected in a child based on the typical MP together with uncertain GI symptoms, a screening test is preferable. According to the recommendations for management 2010, baseline colonoscopy and upper GI endoscopy should be performed at the age of 8 [2]. While Goldstein et al. [13] suggested an earlier initial screening age might be beneficial for children suspect of PJS. 
Table 2 Information about genotype-phenotype correlation of STK11 mutations in PJS

\begin{tabular}{|c|c|c|c|c|c|c|c|}
\hline \multirow[t]{2}{*}{ First author } & \multirow[t]{2}{*}{ Year } & \multirow[t]{2}{*}{ Country } & \multirow[t]{2}{*}{ Subjects $^{a}$} & \multirow{2}{*}{$\begin{array}{l}\text { Mutation } \\
\text { detection rate }\end{array}$} & \multicolumn{2}{|c|}{ Germline mutation } & \multirow[t]{2}{*}{ Clinical risk suggestion } \\
\hline & & & & & Site & Type & \\
\hline Wang [17] & 2014 & China & 35 & $67.3 \%$ & Exon 7 & - & High incidence of Gl polyp dysplasia \\
\hline van Lier [4] & 2011 & Netherlands & 77 & $96.3 \%$ & - & - & Independent of STK11 mutation status \\
\hline Mehenni [18] & 2007 & Switzerland & 27 & $28.7 \%$ & - & - & No significant influence \\
\hline Mehenni [19] & 2006 & EU, AS & 40 & $26.8 \%$ & Exon 6 & - & Higher risk of cancer \\
\hline Hearle [20] & 2006 & $E U, A U, U S$ & 297 & $70.9 \%$ & - & - & No significant influence \\
\hline Schumacher [21] & 2005 & b & 132 & - & $\begin{array}{l}\text { Exon } 1-7 \\
- \\
\text { Exon } 4-5\end{array}$ & $\begin{array}{l}\text { Deletion } \\
\text { Splice site } \\
\text { Missense }\end{array}$ & $\begin{array}{l}\text { Rarely associated with cancer } \\
\text { Significantly associated with cancer } \\
\text { Associated with malignancies }\end{array}$ \\
\hline $\operatorname{Lim}[22]$ & 2004 & $E U, A U, U S$ & 78 & $32.5 \%$ & Exon 3 & - & Higher cancer risk \\
\hline
\end{tabular}

a Subjects with detected STK11 mutation. ${ }^{\text {b}}$ Subjects most from the literature. - No data

EU Europe, AS Asia, AU Australia, US United States

The recommendation screening methods include gastroscopy and colonoscopy, but the situation here emphasizes the importance of follow-up after a negative initial endoscopy. In PJS, polyps prefer to be located in small bowel rather than in stomach or colon, so it is necessary to exam the small bowel when there is no findings in the stomach and colon. With the help of DBE, small bowel polyps can be detected and resected before they cause complications such as intussusception and obstruction due to GI polyps, and open surgeries can be largely avoided [14]. Belsha et al. [15] proved that polypectomy by DBE is effective in managing pediatric patients with PJS by a cohort of 16 patients with 6 years follow-up. Another lesson brought by this case is that PJS polyps are easy to grow in children, which justifies the close followup after negative endoscopy. All above, we suggest DBE is the proper choice after negative gastroscopy and colonoscopy if GI symptoms persist. Luckily, no severe GI complications happened to her before she received DBE. In our experience of managing 131 PJS patients who had abdominal surgeries for intestinal obstruction before, 86 . $3 \%$ (113) of them avoided a second open surgery with the help of regular follow-up by DBE [16].

\section{Abbreviations \\ ACMG: American College of Medical Genetics and Genomics; DBE: double- balloon enteroscopy; Gl: gastrointestinal; HGMD: Human Gene Mutation Database; MP: mucocutaneous pigmentation; PCR: polymerase chain reaction; PJS: Peutz-Jeghers syndrome; STK11: Serine/threonine kinase 11}

\section{Acknowledgements}

We thank the subjects for their participation. We appreciate very much for Dr. Wen-Sheng LIN's kindly help with the pathologic pictures of the polyps. We also appreciate Dr. Liang-Liang ZHU's help with the cost benefits information.

\section{Funding}

This work was supported by National Natural Science Foundation of China (81500490), Application Research of Capital Clinical Character (Z151100004015215) and Annual Project of Air Force General Hospital (KZ2015026 and KZ2016021).

\section{Availability of data and materials}

The datasets used and analysed during the current study available from the corresponding author on reasonable request.

\section{Authors' contributions}

$J$ and XWJ collected the samples and did the follow-up. YL and ZYZ performed experiments and did the analysis. BRL designed the study and supervised the study. ZYZ wrote the manuscript. EDY and SBN supervised the study and revised the manuscript. All of the co-authors have read this manuscript and support this submission. All authors read and approved the final manuscript.

\section{Ethics approval and consent to participate}

This study was approved by the Medical Ethics Committee, Airforce General Hospital of PLA and complied with the Declaration of Helsinki. The approval number of this study is AFGHEC2016145. All of the adult participants including the girl's parents as her guardians were informed to participate in this study with written consents during her stay in our department.

\section{Consent for publication}

Written informed consents for publication of their clinical details and images were obtained from the adult patients. The consents were also obtained from the girl's parents as her guardians during her hospitalization.

\section{Competing interests}

The authors declare that they have no competing interests.

\section{Publisher's Note}

Springer Nature remains neutral with regard to jurisdictional claims in published maps and institutional affiliations.

Received: 4 January 2018 Accepted: 13 April 2018

Published online: 23 April 2018

\section{References}

1. Giardiello FM, Brensinger JD, Tersmette AC, Goodman SN, Petersen GM, Booker SV, Cruz-Correa M, Offerhaus JA. Very high risk of cancer in familial Peutz-Jeghers syndrome. Gastroenterology. 2000;119(6):1447-53.

2. Beggs AD, Latchford AR, Vasen HF, Moslein G, Alonso A, Aretz S, Bertario L, Blanco I, Bulow S, Burn J, et al. Peutz-Jeghers syndrome: a systematic review and recommendations for management. Gut. 2010;59(7):975-86.

3. Massa G, Roggen N, Renard M, Gille JJ. Germline mutation in the STK11 gene in a girl with an ovarian Sertoli cell tumour. Eur J Pediatr. 2007;166(10):1083-5.

4. van Lier MG, Westerman AM, Wagner A, Looman CW, Wilson JH, de Rooij FW, Lemmens VE, Kuipers EJ, Mathus-Vliegen EM, van Leerdam ME. High cancer risk and increased mortality in patients with Peutz-Jeghers syndrome. Gut. 2011;60(2):141-7.

5. Zhao ZY, Jiang YL, Li BR, Yang F, Li J, Jin XW, Ning SB, Sun SH. Sanger sequencing in exonic regions of STK11 gene uncovers a novel de-novo germline mutation (c.962_963delCC) associated with Peutz-Jeghers syndrome and elevated cancer risk: case report of a Chinese patient. BMC Med Genet. 2017;18(1):130

6. Biasini M, Bienert S, Waterhouse A, Arnold K, Studer G, Schmidt T, Kiefer F, Gallo Cassarino T, Bertoni M, Bordoli L, et al. SWISS-MODEL: modelling 
protein tertiary and quaternary structure using evolutionary information. Nucleic Acids Res. 2014;42(Web Server issue):W252-8.

7. Giardiello FM, Trimbath JD. Peutz-Jeghers syndrome and management recommendations. Clin Gastroenterol Hepatol. 2006;4(4):408-15.

8. Hemminki A, Tomlinson I, Markie D, Jarvinen H, Sistonen P, Bjorkqvist AM, Knuutila S, Salovaara R, Bodmer W, Shibata D, et al. Localization of a susceptibility locus for Peutz-Jeghers syndrome to 19p using comparative genomic hybridization and targeted linkage analysis. Nat Genet. 1997;15(1):87-90.

9. Yang HR, Ko JS, Seo JK. Germline mutation analysis of STK11 gene using direct sequencing and multiplex ligation-dependent probe amplification assay in Korean children with Peutz-Jeghers syndrome. Dig Dis Sci. 2010; 55(12):3458-65.

10. Hanks SK, Quinn AM, Hunter T. The protein kinase family: conserved features and deduced phylogeny of the catalytic domains. Science. 1988; 241(4861):42-52.

11. Boudeau J, Baas AF, Deak M, Morrice NA, Kieloch A, Schutkowski M, Prescott AR, Clevers HC, Alessi DR. MO25alpha/beta interact with STRADalpha/beta enhancing their ability to bind, activate and localize LKB1 in the cytoplasm. EMBO J. 2003:22(19):5102-14.

12. van Lier MG, Mathus-Vliegen EM, Wagner A, van Leerdam ME, Kuipers EJ. High cumulative risk of intussusception in patients with Peutz-Jeghers syndrome: time to update surveillance guidelines? Am J Gastroenterol. 2011;106(5):940-5.

13. Goldstein SA, Hoffenberg EJ. Peutz-Jegher syndrome in childhood: need for updated recommendations? J Pediatr Gastroenterol Nutr. 2013;56(2):191-5.

14. Burke CA, Santisi J, Church J, Levinthal G. The utility of capsule endoscopy small bowel surveillance in patients with polyposis. Am J Gastroenterol. 2005;100(7):1498-502.

15. Belsha D, Urs A, Attard T, Thomson M. Effectiveness of double-balloon Enteroscopy-facilitated polypectomy in pediatric patients with PeutzJeghers syndrome. J Pediatr Gastroenterol Nutr. 2017;65(5):500-2.

16. Zhang ZC, Li BR, Li X, Ning SB, Mao GP, Zhang YF, Bu XH, Tang J, M Z, Jin $X W$. Location,growth and clinical outcome of polyps of patients with PeutzJeghers syndrome. Chin J Digestion. 2016;36(9):593.

17. Wang Z, Wu B, Mosig RA, Chen Y, Ye F, Zhang Y, Gong W, Gong L, Huang F, Wang X, et al. STK11 domain XI mutations: candidate genetic drivers leading to the development of dysplastic polyps in Peutz-Jeghers syndrome. Hum Mutat. 2014;35(7):851-8.

18. Mehenni H, Resta N, Guanti G, Mota-Vieira L, Lerner A, Peyman M, Chong KA, Aissa L, Ince A, Cosme A, et al. Molecular and clinical characteristics in 46 families affected with Peutz-Jeghers syndrome. Dig Dis Sci. 2007;52(8):1924-33.

19. Mehenni H, Resta N, Park JG, Miyaki M, Guanti G, Costanza MC. Cancer risks in LKB1 germline mutation carriers. Gut. 2006;55(7):984-90.

20. Hearle N, Schumacher V, Menko FH, Olschwang S, Boardman LA, Gille JJ, Keller $J$ J, Westerman AM, Scott RJ, Lim W, et al. Frequency and spectrum of cancers in the Peutz-Jeghers syndrome. Clin Cancer Res. 2006;12(10):3209-15.

21. Schumacher V, Vogel T, Leube B, Driemel C, Goecke T, Moslein G, RoyerPokora B. STK11 genotyping and cancer risk in Peutz-Jeghers syndrome. J Med Genet. 2005;42(5):428-35.

22. Lim W, Olschwang S, Keller JJ, Westerman AM, Menko FH, Boardman LA Scott RJ, Trimbath J, Giardiello FM, Gruber SB, et al. Relative frequency and morphology of cancers in STK11 mutation carriers. Gastroenterology. 2004; 126(7):1788-94.

\section{Ready to submit your research? Choose BMC and benefit from:}

- fast, convenient online submission

- thorough peer review by experienced researchers in your field

- rapid publication on acceptance

- support for research data, including large and complex data types

- gold Open Access which fosters wider collaboration and increased citations

- maximum visibility for your research: over $100 \mathrm{M}$ website views per year

At BMC, research is always in progress.

Learn more biomedcentral.com/submissions 